The Chemical Block, housing activities in soil science and agricultural chemistry, contains forty rooms fitted up for work in general analytical chemistry, micro-analysis, microbiology, soil physics, physical chemistry and plant chemistry. In addition, there are underground rooms where even temperatures can be maintained, laboratory workshops, a pot-culture house and lysimeters. A new feature of the Chemical Block is a laboratory for carrying out small investigations on the utility of agricultural products and to devise ways and means for the making of intermediate products. The need for this was recognized in 1921 by the Board of Agriculture in India.

In the Entomological Block are a main laboratory, a parasite laboratory and underground constant-temperature rooms. The rooms containing the collections have about 10,000 species represented by hundreds of thousands of specimens both pinned and in alcohol.

The Mycological Block has similarly rooms for use as laboratories, as constant-temperature rooms, as culture rooms and as herbaria, the last named containing a very valuable collection of fungi.

There is a group of buildings consisting of a dairy cattle byre with modern fittings, a veterinary dispensary, bull runs, sheds for sick animals and for segregation, and sheds for implements.

No mention of the Institute would be complete without a mention of what is a great attraction to visitors, namely, the famous Pusa pedigree Sahiwal herd. This is one of the finest herds of milch cattle in India. It has been in existence since 1904, when fourteen cows and one bull were purchased from the Punjab. It has gradually been selected from homebred stock with occasional fresh blood from outside. The average milk yield per cow per day has risen from $5 \mathrm{lb}$. in 1914 to $22 \mathrm{lb}$. in 1934. The bringing of this herd, numbering 172, from Pusa to Delhi was an achievement in itself, a special train being required, taking four days on the journey. There was no break in the recording of milk yields or of the routine of the herd during the transit, and the animals arrived at Delhi in first-class condition.

In addition to the research work of the Institute, there is also its educational activity. This takes the form of two-year postgraduate courses in which the student specializes in one or other of the subjects botany, chemistry, entomology or mycology, and in which the current research work of the Institute is the background of the teaching. Since the inception of this course in 1923, fifty-six students have passed out from the Institute, of which number forty-six have obtained employment either in provincial or State departments of agriculture or under schemes financed in whole or in part by the Imperial Council of Agricultural Research. There is also given a one-year course in farm management, and as occasion or need arises, short courses in special subjects such as the fluecuring of tobacco are arranged.

Lord Curzon, when laying the foundation stone of the original Pusa Institute, remarked that he would like to visit the place in fifty years time and see what it had grown into. He said, "Should I find Pusa the centre of a great organization, with ramifications extending to all parts of the Indian Continent, training a series of students who will devote their acquired knowledge to the practical pursuit of agriculture and able to point to the tangible results of successful scientific experiment, both in the quality of seeds and plants, in the destruction of pests, and in improvement of breeds of cattle? That is the prospect that I should like to look forward to, and if it be at all realized then we may be assisting at a rather momentous childbirth to-day."

The now twice-born Institute faces the future with the means and the will to carry on to still completer realization this prophetic vision.

\title{
Chronological Problems in the Prehistory of North Africa
}

$\mathrm{I}^{\mathrm{m}}$ MPORTANT questions relating to the antiquity of 'fossil' man in North Africa and to the dating and cultural affinities of the later stone age civilization of North Africa and the Sahara are debated by M. R. Vaufrey, of the Institut de Paléontologie humaine, Paris, in two recently published papers*.

* Vaufrey, R, "'L'Age des Hommes Fossiles de Mechta el-Arbi". * Vaufr. Soc. Historique et Géographique de la Réfion de Sétif (1935). Bull. Soc. Historique et Gégraphique de la Rétion de Setif (1935). Vaufrey, R., "L'Age de l'Art rupest
Préhistorique Frangaise, 33, No. 11.
In the first of these, M. Vaufrey has assembled and examined critically the evidence bearing on the age of the skeletal remains and artefacts found in the "escargotières" of Mechta el-Arbi, Tunisia. This midden site was discovered in 1907; but knowledge of its content is imperfect. Owing to the dispersal of the collections both of human remains and artefacts made by $M$. A. Débruge, to whom the exploration of the site was entrusted in 1913 and again in 1923, only one of the four skulls 
then found is now available, housed in the Institut de Paléontologie humaine. The remaining three, with an additional specimen, are represented by casts. There are also casts of a maxilla and a mandible, while there are two mandibles at Constantine, of which one probably belongs to the Mechta el-Arbi type. The Mechta el-Arbi type has also been recognized in the skeletons from the Ibero-Maurusian cave of Afalou bou Rhummel.

The archæological material obtained from M. Débruge's investigations is also only imperfectly represented in collections, while the material obtained by the archæological mission of the Logan Museum (Beloit, Wis.) in 1926-27, though on a more extended scale, does not include a fully representative series of characteristic microliths owing to defects in the technique of excavation.

Nevertheless, the industry revealed by these investigations-an entirely microlithic industryis not Capsian; and when the geometric microliths and the microburins, previously overlooked, are added, it conforms with the industries of Ain Rhilane, Relilaï and a number of other sites of the same culture in the region of Sétif. These all belong to the upper Capsian-the middle Capsian being a purely hypothetical culture, which has never been described anywhere-or to a neolithic with Capsian tradition.

It follows that no greater antiquity than that of this culture can be ascribed to man of Mechta el-Arbi. In other words, Mechta el-Arbi man belongs to the Mesolithic age. Further, it also follows that Capsian man is still unknown. Other skeletal remains, such as those from Djebel Rocknia and Djebel Fartas, and the skeletons secured in $\mathbf{1 8 9 0}$ by M. Pallary from caves in the neighbourhood of Oran, do not go back beyond the neolithic of Capsian tradition.

This neolithic of Capsian tradition marks the point when a neolithic culture with pottery, polished axes, querns for corn-grinding, and bifacial arrow-heads, broke in on an upper Capsian culture at the moment when the local industry was on the way to developing the arrow-head with transverse cutting edge. One result of the impact was the magnificent efflorescence of naturalistic rupestral art. This impact came from Egypt across Libya with the time-lag natural in all colonial development.

The age and affiliations of this culture, as found in association with the rupestral art in North Africa, are discussed further by M. Vaufrey in the second of the papers to which reference is made above. It opens with the critical examination of a statement made by M. M. Reygasse, which claimed a relatively high antiquity for certain rock engravings of the Sahara on the evidence of the discovery here for the first time of the spiral with figures of a fauna now extinct, or no longer found locally, such as, for example, the hippopotamus. M. Reygasse had argued further that this evidence showed that the spiral in the Sahara was independent of the Mediterranean, and that in the Hoggar and Tassili des Adjers it was older than the classical spiral of the eastern Mediterranean; while in addition it indicated that these engravings were much more ancient than the paintings showing the Garamantian vehicles.

M. Vaufrey compares the engravings of the Hoggar and Tassilli des Adjers with those from Oued Chreaa in southern Oran, suggesting that these may well be the work of the same artists and belong to the same epoch. He maintains, however, that the extinction of the fauna, which is made the basis of the argument, may not have taken place at so remote a date as stated. It is frequently advanced on the evidence, inter alia, of the occurrence of a neolithic industry rich in green stone necklace beads in a cave in the central Sahara, that the desiccation of this region is of relatively recent date; while faunal evidence has been adduced in support of a neolithic pluvial phase in the Sahara extending from the middle of the sixth to the middle of the second millennium B.c.

It has been established by an investigation of a number of stations in Oran, some thirty in all, that the culture associated with the rock engravings is the neolithic with Capsian tradition. By the action of time and weather, this culture is not always represented in its entirety; the pottery, in particular, has usually disappeared. It is, however, better represented in more sheltered conditions, such as are found in the caves of El Arouia, north-north-east of Brézina, where a microlithic industry is associated with a class of pottery, in which the fundamental element is a type with pointed base, richly ornamented with incised decoration and frequently provided with lugs. There is also an abundance of polished axes of various kinds of stone, cylindrical or lenticular in section, as well as querns and mullers for grinding corn. In one of these caves was a naturalistic representation of one of the Equidæ and of a member of the ox family engraved on a stone. This industry was found in the north on the very borders of Oran, and from the evidence of the skeletons found by M. Pallary in 1890, its authors are known to have been of the type of the men of Mechta el-Arbi.

The pointed vases afford a new chronological element. They belong to the type found in the Gerzean culture of Negadeh in Upper Egypt of the predynastic epoch. In the same culture are found the earliest spirals, which appear on the painted ware with rounded base and with lugs, 
dating approximately from 4,000 B.c. Among a number of other indications of affiliation is the Libyan sheath, shown on figures at Fedjet el Khaïl and Kharrouba, which links with the Amratians, the predecessors of the Gerzeans, dating from $5,000-4,000$ B.c., while an individual at Kharrouba holds a boomerang, which appears also among the Badarians of predynastic Egypt. Finally, the polished axes, the biface arrow-heads, and the harpoons and the fish-hooks of bone, which in North Africa extend as far as Mauretania, also appear in the earliest neolithic civilization of Egypt, the Tasian of the Fayum and Merimde, while the arrow-heads with transverse cuttingedge are found in the Amratian culture.

The neolithic with Capsian tradition of Oran is thus seen to comprise a number of features which derive from Egypt, but are found there as elements in cultures which succeed one another in a period extending from 6,000 to 4,000 B.C. In the Sahara these features appear more or less contemporaneously, as is shown not only by surface finds, but also on stratified sites. Hence the impression left by this neolithic culture of Capsian tradition is that it has been built up on a Capsian foundation by a succession of borrowings from the neolithic cultures of Egypt. It is a colonial culture, and like all such, is affected by a time-lag. Thus, for example, the head of a ruminant surmounted by a disk first appears in Egypt in the Amratian culture. The same figure, accompanied by bovides and ovides, appears in North Africa, but probably dating from the Middle Kingdom. Another example of the same kind is the painted representations of vehicles, which have been attributed variously to the Garamantes and other sources. The simplest explanation is that these paintings are the work of natives who had been in contact with Egypt under the New Empire, but certainly after the introduction of the horse and chariot into Egypt by the Hyksos. This would give a dating for the culture associated with these paintings, or of those representing the horse alone, such as that at Oued Chreaa, of $1,500-1,000$ B.c.

While $3,500-4,000$ B.c. would thus represent the extreme upward limit of dating for the neolithic culture of Capsian tradition, the gap which exists between this culture and the Mousterian or Aterian in southern Oran and probably throughout the whole of the Sahara, leads to the conclusion that no naturalistic engraving in the whole of this region is older than the neolithicoCapsian culture which is found in association with this North African school of art.

\section{Natural Colour Eclipse Photography}

$\mathrm{T}$ HE first natural colour photograph of a total eclipse of the sun ever reproduced appears in the February issue of the National Geographic Magazine. The original photographs were taken on June 19, 1936, at Ak Bulak in Siberia, by Irvine C. Gardner, leader of the National Geographic Society and U.S. National Bureau of Standards Joint Eclipse Expedition.

Dr. Gardner, in his very interesting article describing the general circumstances of the observations, states that six exposures on Dufay colour plates (of $1,2,4,8,16$ and 8 seconds respectively) were made with a specially designed lens of 9 inches aperture and 19-feet focal length. The camera was fixed, being pointed directly at the eclipsed sun, and the plate holder moved to compensate for the solar motion. The solar image had a diameter of almost two inches. One of the photographs is reproduced in colour among the illustrations to the article.

It is perhaps scarcely fair to judge the original photographs by the reproduction, though there is no mention in the text of any differences between the original and the reproduction. The detail shown is, as one would expect, less than in the usual 'black and white' pictures, but all the main structure of the corona is visible, and the image extends to about a solar radius from the limb of the sun. The sky background is reproduced as a brownish-grey, rather than indigo, and the corona itself is distinctly pink, though it is pearly white to bluish to the eye. The prominences show whitish to blue, and this seems to be nearer the truth than the common idea of a vivid scarlet.

The precise object of these photographs is not stated in the article, which is a popular account, but despite these defects as pictures corresponding to direct eye observation, these pioneer attempts at colour photography of eclipses are of enormous interest, for to the astronomers it matters little whether the photograph looks like the original. The important thing is whether there exists a one to one correspondence between the spectral composition of the radiation reaching us from the corona and prominences and the radiation transmitted by the photograph ; or, to be more exact, can the spectral intensity curve of the source be deduced from the spectral absorption curve of the photograph? 